\title{
Bahasa: Antara Pikiran Dan Tindakan
}

\author{
Mudjia Rahardjo \\ Staf Pengajar UIIS Malang Kandidat Doktor Unair Surabaya \\ "Andaikan orang bodoh tak bicara, maka dunia akan tenang \\ sebab tidak ada kekacauan sosial akibat kesalahan berbahasa" Mustafa Bisri
}

\begin{abstract}
Language, idea and action are closely related. It start from cultivating an idea expressed in a language which creates an action. In certain extent, however, language does not perfectly picture what we think, feel and understand. As a result, what we express in language is not necessarily the same as what we expect. This might create misunderstandings. From this point of view, language doesn't merely consist of words constructed in certain patterns suitable with certain grammatical rules, but language should also deliver the intended message.
\end{abstract}

\section{A. Pengantar}

Tak siapapun menyangkal peran penting bahasa dalam kehidupan manusia. Dengan bahasa, manusia dapat saling berkomunikasi dan mengembangkan ilmu pengetahuan serta kebudayaan dalam rangka membangun peradaban yang lebih baik. Begitu penting peran bahasa, seorang filsuf bahasa kenamaan Ludwig Wittgenstein menyatakan "Die Grenze meiner Sprache bedeuten die Grenze meiner Welt (Batas bahasaku adalah batas duniaku). Secara lebih bebas artinya adalah batas dunia manusia identik dengan batas bahasa logika yang dibangunnya. 
Lebih dari sekadar pernyataan biasa, ungkapan Wittgenstein menyiratkan makna bahwa kemampuan berbahasa seseorang sangat menentukan sejauh mana dia mampu menembus batas-batas dunianya sendiri. Adalah bahasa yang membedakan manusia dari makhluk-makhluk ciptaan Tuhan lainnya. Sebab, hanya manusia yang dapat memproduksi sistem bunyi (sound system) yang demikian kompleks. Selain itu, bahasa juga menunjukkan kondisi psikologis dan intelektual seseorang. Orang yang pikirannya sedang kacau, bisa dipastikan bahasanya juga kacau. Menurut Samsuri kemampuan berbahasa menunjukkan kemampuan otak seseorang. Orang yang bahasanya kacau-baik lisan maupun tulis-hampir bisa dipastikan kemampuan otaknya juga kacau. ${ }^{1}$ Mengutip seorang ahli bahasa terkemuka dari Amerika Tony Crowley, Samsuri menyatakan bahwa kekacauan berbahasa merupakan penyebab terjadinya kekacauan sosial. ${ }^{2}$

Peran penting lainnya adalah sebagai anak sah peradaban yang pertama, bahasa menyimpan seluruh warisan peradaban manusia. Pencarian makna sejarah suatu bangsa, misalnya, dilalui lewat bahasa, sebab ke dalam bahasalah bangsa tersebut menitipkan seluruh pesan, harapan, cita-cita dan pengalaman hidup mereka bagi generasi berikutnya.

Kendati perannya begitu penting, bahasa belum memperoleh perhatian untuk dikajirenungkan secara mendalam dan berkelanjutan. Menurut Bloomfield ${ }^{3}$, bagi kebanyakan orang, bahasa dianggap sebagai sesuatu yang biasa, sehingga berbahasa pun dipandang sebagai peristiwa sederhana sebagaimana bemafas, berjalan, tidur dan sebagainya. Asosiasi yang segera muncul ketika membicarakan bahasa adalah aktivitas berbicara. Jika pengertian bahasa banya dimaknai pada berbicara, maka unsur pokok dalam bahasa hilang, karena berbahasa melibatkan pikiran, emosi dan tindakan.

Untuk ikut berpartisipasi dalam seminar hari ini sekaligus meramaikan acara English Days, saya menyusun naskah singkat yang menguraikan tentang talitemali antara bahasa, pikiran, dan tindakan sosial dalam renungan filsafat. Tema ini sengaja saya pilih di tengah-tengah semaraknya kesalahpahaman, kesalahkaprahan, dan ketidakjelasan serta kesemrawutan berbahasa masyarakat kita. Uraian difokuskan pada relasi antara bahasa, pikiran dan kekacauan sosial. 


\section{B. Antara Berpikir dan Berbahasa}

Hubungan antara pikiran dan bahasa sudah menjadi perhatian para psikolog, filosof, dan antropolog sejak zaman Boas, Sapir dan Whorf. Boas, misalnya, mengatakan adanya hubungan timbal balik antara bahasa dan pikiran. Bahasa merupakan 'cermin budaya pemakainya. Hipotesis yang dikemukakan oleh Sapir dan Whorf itu kemudian dikenal dengan hipotesis Sapir-Whorf, yang juga disebut teori relativisme bahasa.

Lebih jauh dari tesis Sapir-Whorf, para ahli psikolinguistik meyakini bahwa berbicara melibatkan dua dimensi, yakni dimensi internal dan eksternal. Dimensi internal ialah situasi psikologis dan intensi atau kehendak pikir, sedangkan dimensi eksternal ialah tindakan menafsirkan dan mengekspresikan kehendak batin dalam bentuk wujud lahir, yaitu kata-kata yang ditujukan kepada orang lain. Menurut Hidayat ${ }^{5}$, karena berbicara melibatkan penafsiran kehendak batin, maka tidak semua yang kita ucapkan selalu berhasil mewakili isi hati dan benak kita. Itu sebabnya sering terjadi bahwa apa yang kita ucapkan tidak sama dengan apa yang kita kehendaki. Lebih parah lagi jika yang kita kehendaki dan kita ucapkan tidak sama dengan yang kita lakukan. ${ }^{6}$

Contoh yang jelas dari kasus ini adalah kalau kita mengarang. Setelah menulis beberapa paragraf bahkan beberapa halaman, kita mengganti tulisan tersebut karena setelah kita baca ternyata tidak sesuai dengan yang kita kehendaki. Di sini terjadi jarak antara intensi batin dan kemampuan mengekspresikan dalam tulisan. Meminjam tesis Polanyi. Di sini terjadi apa yang disebut surplus of knowledge, bahwa yang kita rasakan dan ketahui melalui pengalaman jauh lebih banyak daripada yang mampu kita ungkap, baik secara lisan maupun tulis. ${ }^{7}$ Dengan demikian, suatu realitas-simbolik maupun empirik-merupakan ekspresi dan narasi yang berbicara lebih banyak daripada yang kita ungkapkan. Pengetahuan kita pun, lanjut Polanyi, sebenarnya hanya menyangkut pengetahuan yang bisa diungkap dalam bahasa (articulate knowledge). Artinya, masih begitu banyak pengetahuan manusia yang tak terungkap (pre-articulate knowledge), karena keterbatasan kemampuan berbahasa kita.

Maka tepat jika salah seorang tokoh hermeneutika Heidegger (1889-1976) mengatakan bahwa jarak antara bahasa dan pikiran menjadi sangat dekat ketika seseorang merenung, berpikir dan berbicara tanpa kata dan tanpa tulisan karena di 
saat diam yang aktif adalah bahasa pikiran yang membentang tak terbatas oleh sekat-sekat gramatika mulai dari aspek fonologis, morfologis, sampai sintaksis. Menurut Hidayat ${ }^{8}$, jika hakikat bahasa adalah pikiran dan tidak perlu diekspresikan dalam kata-kata sebagaimana dikatakan Heidegger, muncul pertanyaan di mana fungsi fundamental bahasa?

Bukankah bahasa berfungsi secara fundamental sebagai medium utama berkomunikasi dan berinteraksi dengan orang lain? Mengapa do'a perlu diungkapkan dalam kata-kata padahal Tuhan toh pasti tahu maksud hati manusia? Bukankah kata-kata itu pula yang akhirnya membuat budaya dan peradaban manusia berkenbang? Tidakkah kata-kata yang kemudian menjadi sistem bahasa tulis itu, menurut Russel, yang menyebabkan ilmu pengetahuan berkembang pesat luar biasa seperti sekarang ini?' Dengan demikian, jelas bahwa bahasa bukan sekadar bunyi suara yang memiliki makna berdasarkan kesepakatan anggota masyarakat, sebagaimana definisi konvensionalnya yakni as arbitrary vocal symbols by which members of society make interaction, melainkan juga manifestasi esensi dan eksistensi manusia.

Implikasi dari sederet pertanyaan tersebut, meminjam Hidayat ${ }^{10}$ adalah bahwa tindakan berbahasa mempunyai nilai moral dan eskatologis. Itulah sebabnya kita dianjurkan untuk menghindarkan diri dari berbicara yang tidak benar. Logikanya sederhana; berbicara benar saja bisa disalahartikan, apalagi berbicara salah. Dalam realitas sosial mudah diamati, berbahasa berawal dari pikiran yang tertuang dalam tulisan atau ucapan, dan munculah sekian banyak efek baik negatif maupun positif, sehingga dalam menjelaskan realitas bahasa bersifat enabling di satu sisi dan constraining di sisi yang lain. Maka dari itu, kebenaran bahasa bukan sematamata karena kebenaran susunan gramatikanya, tetapi pada tata pikir, intensi dan implikasi yang muncul dari sebuah ucapan. Intensi yang baik belum tentu melahirkan efek yang baik, dan sebaliknya.

Mengingat terdapat jarak antara kehendak batin dan ucapan lahir, maka ekstemalisasi gagasan tidak pemah selamanya cukup terwadahi hanya dalam satu kata dan kalimat. Untuk memahami gagasan secara utuh diperlukan konteks mengenai kapan, di mana dan dalam situasi apa suatu ucapan muncul. Ucapan yang sama bisa bermakna berbeda dalam konteks yang berbeda pula. Dari sinilah muncul analisis wacana sebagaimana dikembangkan van Dijk ${ }^{11}$ sebagai sebuah pendekatan baru untuk memahami gagasan, ide, dan makna suatu tindakan secara 
lebih komprehensif. Belakangan pendekatan ini telah dikembangkan lebih jauh oleh Fowler $^{12}$ dan Fairclough ${ }^{13}$ melalui Analsis Wacana Krirtis-nya.

Menyadari hubungan antara pikiran, ucapan, dan tindakan yang sedemikian kompleks, maka disadari atau tidak setiap saat kita berada dalam lingkaran dunia penafsiran. Implikasinya, realitas apapun yang tertangkap oleh mata, telinga, dan perasaan kita selalu mengundang kita untuk menafsirkan sebelum memberi respons. Bahkan sebelum mengungkapkan perasaan atau pikiran kepada orang lain atas realitas, kita dituntut untuk melakukan penafsiran-penafsiran gramatikal-kognitif, kultural, sosial, dan psikologis, menyangkut kata dan kalimat bagaimana yang seharusnya diucapkan kepada orang lain tersebut. Dari sini muncul kajian sosiolinguistik sebagaimana dikembangkan Wardhaugh ${ }^{14}$, Chaika ${ }^{15}$, dan sebagainya. Dalam perspektif sosiolinguistik, ketepatan berbahasa menunjukkan jati diri penuturnya ${ }^{16}$. Merujuk konstruksionisme Berger dan Luckman ${ }^{17}$ sosok dan jati diri manusia tidak lebih merupakan hasil konstruksi sosial melalui bahasa

Karena bahasa mencerminkan kualitas pribadi, baik moral maupun intelektual sebagaimana disepakati oleh para pengakaji sosiolingusitik dan psikolinguistik, maka seseorang selalu berusaha untuk berbahasa yang baik agar keberadaannya diterima oleh masyarakat. Namun sangat disayangkan, di masyarakat kita, bahkan di kalangan kaum terdidik, kata-kata yang ditulis dalam bahasa Indonesia yang begitu jelas bisa keliru mengucapkannya. Misalnya, publik diucapkan pablik, pasca dibaca paska, musyawarah dilafalkan musyawaroh, Arab diucapkan Arob, klien diucapkan klain, sukses dibaca sakses, produk dibaca prodak, faks dibaca feks, psikologi diucapkan saikoloji, dapat dibaca dapet, semakin dilafalkan semangkin dan masih banyak lagi yang lain. Inilah cermin konkret perilaku berbahasa masyarakat kita.

Menurut Kridalaksana ${ }^{18}$, pengetahuan mengenai asal usul kata berikut ucapannya memang tidak harus dimiliki oleh setiap orang, tetapi bahasa manapun di dunia ini mempunyai konvensi lafal yang menjadi salah satu rambu kerjasama sosial. Untuk melafalkan unsur-unsur bahasa tidak diperlukan pengetahuan etimologi, karena sudah tersedia kamus yang siap untuk dirujuk setiap saat. Lafal yang tepat itu ibarat pakaian rapi yang memberi suasana nyaman dalam pergaulan manusia yang santun.

Bagi pengkaji sosiolinguistik, kesalahan ucap seperti itu tidak bisa dipandang sekadar slip of the tongue sebagaimana alasan yang dikemukakan ketika orang 
salah ucap, sehingga dianggap sederhana. Bukankah perilaku berbahasa menunjukkan siapa penggunanya baik secara sosial maupun intelektual? Menggunakan perspektif Chaika $^{19}$ sebagaimana disebutkan di atas, maka dengan sangat mudah dikesan dunia batin macam apa yang terjadi pada masyarakat kita dari kekacauan berbahasa seperti itu.

\section{B. Kekacauan Semantik}

Kekacauan berbahasa masyarakat kita ternyata tidak hanya pada tingkat ucapan kata (fonologis), tetapi juga melebar sampai tingkat makna (semantik). Contoh, bagaimana kata "demokrasi" memiliki berbagai makna sehingga menimbulkan kesalahpahaman di masyarakat kita. Seorang pakar ilmu sosial bernama Bertnand de Jouvenel menyatakan bahwa pembahasan tentang demokrasi secara intelektual sama sekali tidak bermanfaat, karena orang tidak mengetahui apa yang dibicarakan ${ }^{20}$. Pengamatan menujukkan bahwa kata tersebut telah diberi pengertian beraneka ragam; di dunia politik dikenal demokrasi sosial, demokrasi ekonomi, demokrasi industri, demokrasi parlementer dan sebagainya.

Di Indonesia dikenal istilah demokrasi liberal, demokrasi terpimpin pada era Soekarno, dan demokrasi Pancasila oleh rezim Soeharto, dan di era Megawati, meminjam istilah Arbi Sanit, dikenal istilah demokrasi semu. Kehidupan sosial politik saat ini banyak yang menyebutnya sebagai "demokrasi kebablasan", yang kesemuanya semakin menujukkan kesemrawutan makna demokrasi. Karena maknanya kabur, maka praktiknya pun menjadi tidak jelas. Makna demokrasi di setiap negara dan rezim berbeda-beda. Lebih luas lagi, apa yang dimaui oleh penguasa atau negara tentang demokrasi bisa berbeda dengan yang dipahami rakyat. Maka itu sebabnya, membangun demokrasi di Indonesia sulitnya luar biasa.

Demokrasi memang bukan konsep lokal warisan nenek moyang kita, tetapi merupakan konsep Barat, sehingga kita mengkonstruksi sendiri maknanya seiring dengan tuntutan demokratisasi di berbagai bidang kehidupan. Karena konsep demokrasi tidak pernah diajarkan-atau tidak dianggap penting oleh nenek moyang kita-sehingga kita menjadi asing dengan praktik kehidupan "berdemokrasi", maka wajar jika kita mengalami kesulitan mencari padanan kata tersebut. Karena bahasa merupakan realitas simbolik, maka kata hakikatnya adalah representasi realitas. 
Implikasinya, kalau realitas tidak ada, maka kata tidak tercipta. Bandingkan dengan kata rice ${ }^{21}$ dalam bahasa Inggris yang dapat diungkap dengan sejumlah kata yang spesifik dalam bahasa Indonesia: padi, gabah, beras, nasi, lontong, upo (Jawa) dan sebagainya.

Dengan banyaknya ragam kata yang berbubungan dengan hajat hidup ini bisa ditafsir bahwa kita memang diajar untuk 'hidup", karena itu tidak boleh lapar, tetapi tidak diajarkan bagaimana mengisi 'kehidupan'. Dalam falsafah Jawa kita kenal istilah 'pokoke urip' (asal hidup). Tafsir ini tampaknya benar dengan merujuk teori hubungan antara bahasa, pikiran dan budaya Franz Boas ${ }^{22}$

Boas, Franz. 1974. "Introduction to the Handbook of American Indian Language", bahwa setiap bahasa merepresentasikan klasifikasi pengalaman dan budaya masyarakat.

Contoh sejenis menjadi panjang lagi lewat kajian Rosidi ${ }^{23}$ yang menemukan betapa banyak kata atau istilah yang menggambarkan kekerasan, seperti tabok, pukul, jitak, tinju, jotos, bogem, tonjok, tunjek, sodok, tempeleng, gebuk, tampar, sikat, timpuk, dan hantam. Mengapa demikian banyak kata yang berhubungan dengan tindak kekerasan tersebut? Mengikuti teori Boas tentang hubungan bahasa dan budaya, bukankah itu semua menunjukkan dengan gamblang gambaran budaya masyarakat kita yang suka kekerasan? Dengan demikian jelas bahwa semula berbahasa adalah dorongan natural, namun sekaligus bahasa adalah fenomena kultural sehingga kemampuan berbahasa tidak bisa diwariskan secara genetik. Orangtua yang baik kemampuan berbahasanya tidak berarti anaknya juga akan baik. Demikian pula orangtua yang kebetulan bisu, tidak berarti anaknya menjadi bisu pula.

Belum tuntas mengenai ketidakjelasan konsep demokrasi sebagaimana diungkap di atas, belakangan kita disibukkan dengan istilah 'wacana', Sejak era reformasi bergulir, istilah 'wacana' menjadi demikian intensif diucapkan berbagai kalangan. Masalah apapun dijadikan wacana. Ribut-ribut upaya melengserkan Megawati oleh beberapa elemen mahasiswa dikatakan sekadar 'wacana'. Setiap ada isu kenaikan harga BBM, pemerintah selalu menyatakan semuanya hanya 'wacana'. Demikian pula dengan rencana pemerintah untuk memutuskan hubungan diplomatik dengan Swedia karena melindungi tokoh GAM (Gerakan Aceh Merdeka), ada elit politik yang mengatakan rencana itu baru sebatas 'wacana'. 
Tampaknya dari semua ungkapan mengenai 'wacana' dapat disimpulkan bahwa kata wacana diberi makna sebagai 'gagasan awal yang belum matang dan sengaja dilontarkan untuk memperoleh tanggapan publik'., maka Gus Dur ketika menjadi presiden dianggap tokoh yang suka membuat 'wacana'. Atau arti lain yang tidak jauh dari rumusan itu adalah 'sekadar percakapan atau obrolan' karena itu tidak perlu ditanggapi secara serius ${ }^{24}$.

Para linguis dan peminat studi linguistik merasa sangat berkepentingan untuk meluruskan makna kata wacana tersebut sesuai aslinya agar tidak menimbulkan kekacauan lebih jauh. Sebermula kata wacana digunakan oleh para ahli bahasa untuk mencari padanan istilah discourse atau diskursus dalam bahasa asing. Mereka menemukan istilah wacana sebagai padananannya yang dianggap cocok atau sesuai maksud yang terkandung dalam istilah asing tersebut. Kamus Inggris-Indonesia John Echols-Hassan Shadily ${ }^{25}$ memberi makna wacana sebagai pidato, atau tulisan, percakapan, ceramah.

Sementara Webster's New World College Dictionary ${ }^{26}$ di antaranya mendefinisikan discourse sebagai (1) communication of ideas, information etc., esp. by talking: conversation, (2) a long and formal treatment of a subject, in speech or writing: lecture; treatise or dissertation, (3) ability to reason; rationality, (4) to speak or write (on or upon a subject) formally at some length. Dari pelacakan ini terlihat jelas bahwa makna kata "discourse" yang berkembang di masyarakat kita berbeda jauh dari makna asalnya dan tak satupun definisi mengenai wacana sebagai "sekadar ( $j u s t$ ) pembicaraan" awal atau gagasan awal. Kita semakin bingung siapa yang memulai memberi makna kata tersebut sebagaimana yang berkembang sekarang.

Berbahasa selalu bersifat publik, artinya bahasa selalu tumbuh bersama di tengah masyarakat. Dalam teori Language Game-nya, Wittgenstein ${ }^{27}$, menyatakan manusia memperlakukan bahasa bagaikan sebuah permainan di mana ada pemain, penonton dan wasit. Sebuah permainan selalu memiliki aturan yang disepakati. Demikian juga berbahasa, tak sesiapapun bisa dengan seenaknya dan secara anarkis memberi makna dan memahami kata apalagi memaksakan makna sesuai yang dikehendaki tanpa melalui proses konvensi yang merupakan ciri fundamental bahasa. Tanpa adanya aturan sebuah permainan dan komunikasi, bahasa akan menciptakan kekacauan yang urutannya bangunan ilmu pengetahuan dan tertib sosial juga akan ikut kacau. 
Dengan demikian, sebuah ungkapan digunakan jelas karena ada kesepakatan dalam masyarakat bahasa tentang maknanya atau aspek semantiknya. Di samping itu perlu kesepakatan untuk apa sebuah kesepakatan dipakai, karena penggunaan ungkapan akan memberi dampak pada khalayak; dengan kata lain, ungkapan itu mempunyai aspek pragmatik. Kalau seorang mengaku bahwa hanya periannya dan maksudnya yang paling benar, akan terjadi kekacauan semantik dan pragmatik, yang biasanya menjadi sumber kekacauan berpikir dan kekacauan berkomunikasi.

\section{Penutup}

Uraian di atas menyiratkan makna bahwa bahasa memiliki dimensi demikian luas bagi kehidupan manusia. Tetapi karena kita lahir dan tumbuh sudah dalam keadaan berbahasa, maka kita tidak bisa bersikap kritis terhadapnya. Berbahasa dianggap sebagai peristiwa biasa. Padahal, karena bahasa realitas menjadi jelas, tetapi lewat bahasa pula semuanya menjadi kabur. Sebab, betapa banyak pengetahuan yang kita rasakan dan lihat ternyata tidak mampu dituangkan dalam kata sehingga kita memilih bahasa diam. Karena itu, sikap diam bukan karena tidak tahu, tetapi karena tidak bisa mengungkapkannya lantaran keterbatasan bahasa.

Mengingat manusia dan bahasa tidak bisa dipisahkan, maka kualitas dan gaya berbahasa seseorang merupakan indikator kualitas kepribadiannya, baik secara kultural, sosial, maupun intelektual. Atas dasar ini, maka bisa ditafsir kondisi batin dan intelektual macam apa jika kesalahpahaman dan kesalahkaprahan berbahasa sedemikian semarak di masyarakat kita yang gilirannya adalah menimbulkan kekacauan sosial.

Berbahasa, dengan demikian, bukan sekadar menyusun kata untuk menjadi kalimat dengan makna yang telah disepakati oleh masyarakat penuturnya, melainkan mencakup banyak variabel. Karena bahasa, pikiran, dan tindakan cenderung menyatu, maka berbahasa adalah mengekspresikan secara total seluruh perasaan dan pikiran yang dituangkan dalam simbol suara, gerak, dan huruf yang kemudian tersusun menjadi kata, kalimat sampai teks yang melahirkan suatu tindakan. Berbahasa yang baik lalu diartikan sebagai mengekspresikan sebuah gagasan secara jelas, teratur, indah, sehingga enak didengar dan tidak menimbulkkan salah paham. 


\section{Mudjia Rahardjo}

\section{Endnotes}

1 Samsuri. 1998. "Bahasa Kacau, Tanda Otaknya Kacau", Jawa Pos, 24 Juni

$2 \quad$ Ibid.

3 Bloomfield, Leonard. 1995. Language. Edisi Indonesia oleh I. Stutikno. Jakarta: PT Gramedia Pustaka Utama, hal. xiii

4 Kartomihardjo, Soeseno. 1998. Pidato Promosi Drs. Agustinus Ngadiman, M.Pd. untuk Memperoleh Gelar Doktor dalam Bidang Pendidikan Bahasa Inggris Tanggal 26 Februari, hal. 1

5 Hidayat, Komaruddin. 1996. Memahami Bahasa Agama: Sebuah Kajian Hermeneutik. Jakarta: Penerbit Paramadina, hal. 43

6 Rahardjo, Mudjia. 2001. Bahasa dan Peradaban: Sebuah Tinjauan Filsafat Pidato Ilmiah Disampaikan pada Rapat Terbuka Senat STAIN Malang dalam Rangka Wisuda Lulusan D2, Sarjana S1. dan Pascasarjana S2, 27 Oktober, hal. 4

7 Polanyi, Michael, 1972, The Study of Man, Chicago: The University of Chicago Press

8 Hidayat, opcit, hal. 41

9 Russel, Peter, 1992, The White Hole in Time: Our Future Evolution and the Meaning of Now, New York: The Acquiran Press

10 Ibid, hal. 43

11 Fowler, R. 1985. "Power", dalam van Dijk, T(Ed.), Handbook of Discourse Analysis Volume t: Discourse Analysis in Society. London: Academic Press

12 Fowler, R. 1985. "Power", dalam van Dijk, T(Ed.), Handbook of Discourse Analysis Volume t: Discourse Analysis in Society. London: Academic Press

13 Fairclough, N. 1995. Critical DiscourseAnalysis; The Critical Study of Language. Harlow-Essex: Longman Group Limited

14 Wardhaugh, R. 1986. An Intraduction to Sociolinguistics. Oxford: Basil Blackwell Ltd.

15 Chaika, Elaine, 1982, Language: The Social Mirror, Rowley: Massachusetts: Newbury House Publishers, Inc.

16 Ibid

17 Berger, Peter L., and Thomas Luckman, 1967, The Social Construction of Reality, New York: Anchor Books

18 Kridalaksana, Harimurti. 1999. "Salah Ucap yang Harus Dihindarkan", Kompas 28 Oktober, hlm. 12

19 Chaika, Op.Cit. 
20 Kridaklaksana, Harimurti. 2000." Etik dalam Semantik dan Pragmatik", Kompas, 19 Mei, hal. 2

2) Suparno. 2000. Budaya Komunikasi yang Terungkap dalam Wacana Bahasa Indonesia. Pidato Pengukuhan Guru Besar dalam Bidang Wacana Bahasa Indonesia pada fakultas sastra Universitas Negeri Malang, Disampaikn pada Sidang Terbuka Senat Universitas Negeri Malang pada tanggal 20 November, hal. 2

22 Boas, Franz. 1974. "Introduction to the Handbook of Anterican Indian Language" dalam Ben G. Blount, Language, Culture and Socieb: Cambridge: Winthrop Publishers, Inc.

23 Rosidi, Sakban, 2001, "Violence Discourse or Discursive Violence? Toward a Reciprocal Model of Relationship between Language and Violence, in Poetica, Journa: of Language and Literature, 1 (1), August 2001, English Program, Merdeka Uriversity Malang. 38

24 Ayatrohaedi. 2002. "Baru Sekadar Wacana", Kompas, 10 Agustus, hal. 12

25 Echols, John M. dan Hasan Shadily. 1978. Kamus Inggris Indonesia: An EnglishIndonesian Dictionary. Jakarta: PT. Gramedia, hal. 185

25 Webster's New World College Dictionary. 1996. New York: A Simon and Schuster Macmillan Company, p. 392

27 Mulkhan, Abdul Munir. 2001. Kiai Presiden, Islam, dan TNI di Tahm-tahun Penentuan. Yogyakarta: UII Press, hal. 42 


\section{Bibliography}

Ayatrohaedi. 2002. "Baru Sekadar Wacana", Kompas, 10 Agustus

Berger, Peter L., and Thomas Luckman, 1967, The Social Construction of Reality, New York: Anchor Books.

Bloomfield, Leonard. 1995. Language. Edisi Indonesia oleh I. Stutikno. Jakarta: PT. Gramedia Pustaka Utama

Boas, Franz. 1974. "Introduction to the Handbook of American Indian Language" dalam Ben G. Blount, Language, Culture and Society. Cambridge: Winthrop Publishers, Inc.

Chaika, Elaine, 1982, Language: The Social Mirror, Rowley: Massachusetts: Newbury House Publishers, Inc.

Echols, John M. dan Hasan Shadily. 1978. Kamus Inggris Indonesia: An EnglishIndonesian Dictionary. Jakarta: PT. Gramedia

Fairclough, N. 1995. Critical DiscourseAnalysis; The Critical Study of Language. Harlow-Essex: Longman Group Limited

Fowler, R. 1985. "Power", dalam van Dijk, T (Ed.), Handbook of Discourse Analysis Volume t: Discourse Analysis in Society. London: Academic Press

Hidayat, Komaruddin. 1996. Memahami Bahasa Agama: Sebuah Kajian Hermeneutik. Jakarta: Penerbit Paramadina

Kartomihardjo, Soeseno. 1998. Pidato Promosi Drs. Agustinus Ngadiman, M.Pd.untuk Memperoleh Gelar Doktor dalam Bidang Pendidikan Bahasa Inggris Tanggal 26 Februari

Kridalaksana, Harimurti. 1999. "Salah Ucap yang Harus Dihindarkan", Kompas 28 Oktober

Kridaklaksana, Harimurti. 2000." Etik dalam Semantik dan Pragmatik", Kompas, $19 \mathrm{Mei}$

Mulkhan, Abdul Munir. 2001. Kiai Presiden, Islam, dan TNI di Tahun-tahun Penentuan. Yogyakarta: UII Press 
Polanyi, Michael, 1972, The Study of Man, Chicago: The University of Chicago Press.

Rahardjo, Mudjia. 2001. Bahasa dan Peradaban: Sebuah Tinjauan Filsafat. Pidato Ilmiah Disampaikan pada Rapat Terbuka Senat STAIN Malang dalam Rangka Wisuda Lulusan D2, Sarjana S1. dan Pascasarjana S2, 27 Oktober Rosidi, Sakban, 2001, "Violence Discourse or Discursive Violence? Toward a Reciprocal Model of Relationship between Language and Violence, in Poetica, Journal of Language and Literature, 1 (1), August 2001, English Program, Merdeka University Malang.

Russel, Peter, 1992, The White Hole in Time: Our Future Evolution and the Meaning of Now, New York: The Acquiran Press.

Samsuri. 1998. "Bahasa Kacau, Tanda Otaknya Kacau", Jawa Pos, 24 Juni.

Suparno. 2000. Budaya Komunikasi yang Terungkap dalam Wacana Bahasa Indonesia. Pidato Pengukuhan Guru Besar dalam Bidang Wacana Bahasa Indonesia pada fakultas sastra Universitas Negeri Malang, Disampaikan pada Sidang Terbuka Senat Universitas Negeri Malang pada tanggal 20 November

Van Dijki. Teeun. 1985. "Introduction: The Role of Discourse Analysis", dalam van Dijk, T. (Ed.), Handbook of Discourse Analysis Volume 4 : Discourse Analysis in Society. London: Academic Press

Wardhaugh, R. 1986. An Introduction to Sociolinguistics. Oxford: Basil Blackwell Ltd.

Webster's New World College Dictionary. 1996. New York: A Simon and Schuster Macmillan Company 
